\title{
Non-accidental head injury in children: medical care direct economic cost in a tertiary care hospital
}

\author{
Arturo Loredo-Abdalá, ${ }^{1}$ Abigail Casas-Muñoz, ${ }^{1}$ Gabriel Alejandro González-Garay, ${ }^{2}$ \\ Raquel Ortiz-Hernandez, ${ }^{3}$ Jessica María González-Corona ${ }^{1}$ and Leslie Viridiana Ramírez-Angoa ${ }^{1}$ \\ ${ }^{1}$ Coordination of Advanced Studies on Child Abuse and its Prevention; ${ }^{2}$ Department of Research Methodology; ${ }^{3}$ Directorate of Planning. Secretaría \\ de Salud, Instituto Nacional de Pediatría, Ciudad de México, Mexico
}

\begin{abstract}
Introduction: Abusive head trauma (AHT) is an extreme form of physical abuse that is produced by abruptly shaking an infant or toddler. Objective: To describe the direct economic cost of care during hospitalization of 14 children with confirmed diagnosis of AHT in a pediatric hospital. Method: Analysis of the cost of disease in patients with AHT attended to between 2001and 2010. Partial direct economic cost of medical care (days of hospital stay, laboratory tests and imaging studies, surgical procedures and subspecialist consultations) was calculated adjusting for inflation, with year 2001 taken as base year. Patients were classified in three groups (moderate, severe and fatal AHT). Descriptive and sensitivity analysis was carried out. Results: Patients with severe AHT generated higher medical care costs $(\$ 105,794.88 \pm 33,201.91)$ in comparison with the group of moderate $(\$ 37,012.95, \pm 7,154.87)$ and fatal AHT $(\$ 18,595.04 \pm 6424.47)(p<0.05)$. Total cost was $\$ 665,467.98$ Mexican pesos (\$71,249.25 international dollars). Conclusions: Total cost for the 14 patients was an elevated figure, as in other parts of the world. The direct economic cost is closely related to the severity of the clinical presentation.
\end{abstract}

KEY WORDS: Child abuse. Shaken baby syndrome. Abusive head trauma. Costs and cost analysis. Medical economics.

\section{Introduction}

Abusive head trauma (AHT) or shaken baby syndrome (SBS) is an extreme form of physical abuse ${ }^{1,2}$ that is produced by abruptly shaking an infant or toddler. This mechanism generates rotation of the head and acceleration and deceleration movements, which can cause the rupture of the communicating vessels of the brain (causing hemorrhages), hypoxia, diffuse brain damage, damage to the cervical spine and to some structures of the eyeball. Intracranial trauma occurs, which, in most cases, does not show external evidence on the skull suggesting internal damage. It manifests itself by a series of clinical and pathological alterations that make up a well-defined syndrome. ${ }^{3,4}$ There is a close relationship between the strength of the sway, its duration and the degree of hypoxia that is generated. Hypoxia triggers cerebral edema with intracranial pressure elevation, and therefore there is blood perfusion lower pressure, thus producing cerebral ischemia and subsequent axonal damage. The higher the hypoxia, the greater the presence of cerebral edema, which is a determinant in clinical evolution that increases severity and, therefore, the cost of medical care..$^{5,6}$

The most common signs and symptoms these patients present with include alterations of the state of consciousness (43 to $77 \%$ ), lethargy (24 to $77 \%$ ), irritability $(7 \%)$, seizures (40 to $76 \%)$, increased or decreased muscle tone, vomiting (15 to $24 \%$ ), food rejection (29\%), breathing disturbances or apnea (34 to $41 \%$ ) and developmental delay or regression (12\%). Most common radiological findings on cranial computerized axial tomography include subdural hemorrhage (29 to $80 \%$ ), subarachnoid hemorrhage (12 to $50 \%)$, intracerebral hemorrhage (8\%), epidural
Date of reception: 07-05-2018

Date of acceptance: $28-08-2018$

DOI: 10.24875/GMM.M19000209
Gac Med Mex. 2018;154:572-581

Contents available at PubMed www.gacetamedicademexico.com 
hemorrhage (4 to $9 \%$ ), parenchymal hemorrhage or injury (9 to $37 \%$ ), cerebral edema (4 to $59 \%$ ), and hygromas (11 to $29 \%$ ). In addition to intracranial injuries, fractures in different parts of the body can be found (mainly ribs and long bones)., ${ }^{4,-10}$ Approximately half of patients with AHT present with severe deterioration, they arrive unconscious or moribund. These patients are often complicated with hypotension and hypoxemia. ${ }^{11}$ Survivors have been reported to have important sequelae: between 55 and $80 \%$ of cases experience severe cerebral atrophy, as well as neurofunctional deficit; follow-up studies have been carried out for 4 or 5 -year periods. Mortality has been reported in 19 to $35 \%$ of cases, which is significant considering that this pathology is $100 \%$ preventable. ${ }^{3,7,10-13}$

The American Academy of Pediatrics indicates an AHT incidence ranging from 17 to $24 \%$ in the United States. ${ }^{3}$ In Mexico, its frequency has not been able to be specified, basically because the diagnosis is not established, and when it is, only isolated reports are made. ${ }^{12,13}$ Notwithstanding, research on this pathology allows to know the clinical picture at home and at admission to the emergency services, its pathophysiology, the required services, as well as morbidity and mortality. ${ }^{14-19}$

One aspect of this pathology that has been scarcely described internationally and has not been described at the national level is the economic impact for the medical institution for its care.

To assess the economic burden of a disease, there are cost-of-illness studies, which identify, quantify and assess associated economic resources. Drummond ${ }^{20}$ recognizes the methodology used to calculate the costs of a disease and considers that the cost of a disease is comprised by three components: direct costs, mainly in charge of the health system for the treatment of disease; indirect costs, in terms of production lost due to morbidity or premature mortality from the disease; and intangible costs, in terms of pain, suffering or quality of life reduction for those who suffer from the disease. ${ }^{20}$

There are only few specific reports on the cost of care for patient victims of AHT and those that have been generated come especially from the United States, where lifetime average cost for an AHT fatality has been estimated to be 5.7 million dollars (95\% $\mathrm{Cl}=3.2-9.2$ million dollars). For patients who survive, average cost in 2010 was estimated to be 257 million dollars for medical care and related direct costs. On that same year, an incidence of 4824 AHT cases was estimated. Lifetime cost of these cases was
13.5 billion dollars ( $95 \% \mathrm{Cl}=5.5-16.2$ billion), including 257 million dollars for medical care, 552 million dollars for special education, 322 million dollars for child protective services/criminal justice, 2 billion for lost work, and 10.3 billion dollars for lost quality of life. ${ }^{21,22}$

The cost of the care of patients with AHT has also been reported to be higher when compared to that of patients with similar socio-demographic characteristics attended to for other causes, especially because they require longer hospitalization time, higher use of medical services at discharge, as well as larger use of medications. ${ }^{23}$ With regard to the cost of care at the department of emergencies and hospitalization at the moment of diagnosis, in the United States, providing care to 6827 patients $(95 \% \mathrm{Cl}=6072-7582)$ in the emergency department and $12,533(95 \% \mathrm{Cl}=10,395$ 14,671) hospitalizations (28\% hospitalized in the same hospital where the emergency department was consulted), the average of this cost was 2,612 dollars for emergency care and 31,901 dollars for hospitalization. ${ }^{24}$

Thus far, the economic cost that implies the specific care of cases with the AHT diagnosis has not been described in Mexico and, therefore, the impact on the administrative sphere of a tertiary care pediatric hospital of our country is not known.

The purpose of this study is to describe the partial economic direct cost generated during the hospitalization of 14 patients with confirmed diagnosis of abusive head trauma in a tertiary care pediatric hospital of Mexico City, at the moment of diagnosis.

\section{Method}

Economic evaluation of the cost-of-illness analysis-type with a retrospective approach, from the perspective of the health care system and only considering healthcare costs,,$^{25}$ over a 10 -year period of, given the low frequency this pathology is detected with. The project was approved by the National Institute of Pediatrics Research Committee, with registration number 026/2016.

Partial direct economic cost of medical care was calculated by reviewing secondary sources: clinical records (physical and electronic), as well as electronic radiological and laboratory records. The target population were patients with confirmed diagnosis of AHT and for whom consultation with the Clinic for Comprehensive Care of the Abused Child of the National Institute of Pediatrics (CAINM-INP - Clínica de Atención Integral al Niño Maltratado del Instituto Nacional de 
Table 1. Characteristics of 14 patients diagnosed with abusive head trauma (AHT) during hospitalization, at diagnosis, and sequels identified during hospitalization

\begin{tabular}{|c|c|c|c|c|c|c|c|c|}
\hline \multirow[t]{2}{*}{ Characteristic } & \multicolumn{2}{|c|}{$\begin{array}{l}\text { Moderate AHT } \\
\quad(n=4)\end{array}$} & \multicolumn{2}{|c|}{$\begin{array}{c}\text { Severe AHT } \\
(n=4)\end{array}$} & \multicolumn{2}{|c|}{$\begin{array}{l}\text { Fatal AHT } \\
(n=6)\end{array}$} & \multicolumn{2}{|c|}{$\begin{array}{c}\text { Total } \\
(n=14)\end{array}$} \\
\hline & $\mathbf{n}$ & $\%$ & $\mathbf{n}$ & $\%$ & $\mathbf{n}$ & $\%$ & $\mathbf{n}$ & $\%$ \\
\hline \multicolumn{9}{|c|}{ Main characteristics at admission that were used to classify AHT severity } \\
\hline Altered state of consciousness at admissior & 1 & 25 & 4 & 100 & 5 & 83 & 10 & 71 \\
\hline Required intubation & 1 & 25 & 4 & 100 & 5 & 83 & 10 & 71 \\
\hline Presence of cerebral edema on cranial CT scan & 0 & 0 & 4 & 100 & 6 & 100 & 10 & 71 \\
\hline Required PICU attention & 0 & 0 & 4 & 100 & 0 & 0 & 4 & 29 \\
\hline \multicolumn{9}{|l|}{ Sequels identified during hospitalization } \\
\hline Motor sequels & 3 & 75 & 4 & 100 & \multicolumn{2}{|c|}{$\mathrm{NE}$} & 7 & 50 \\
\hline Visual sequels & 3 & 75 & 4 & 100 & \multicolumn{2}{|c|}{ NE } & 7 & 50 \\
\hline Auditory sequels & 0 & 0 & 4 & 100 & \multicolumn{2}{|c|}{ NE } & 4 & 29 \\
\hline Speech sequels & 4 & 100 & 3 & 75 & \multicolumn{2}{|c|}{$\mathrm{NE}$} & 7 & 50 \\
\hline Persistence of seizures & 2 & 50 & 4 & 100 & \multicolumn{2}{|c|}{ NE } & 6 & 43 \\
\hline \multirow[t]{2}{*}{ Overall growth retardation } & 2 & 50 & 4 & 100 & \multicolumn{2}{|c|}{$\mathrm{NE}$} & 6 & 43 \\
\hline & Median & Min-max & Median & Min-max & Median & Min-max & Median & Min-max \\
\hline Age in months & 5 & $4-8$ & 7.5 & $2-9$ & 5 & $2-14$ & 6 & $2-14$ \\
\hline
\end{tabular}

Pediatría) was requested for their management, during the 2001 to 2010 period.

\section{Operational definitions and data collection}

The AHT diagnosis was established by the presence of intracranial hemorrhage and retinal hemorrhage, together with a comprehensive assessment by the CAINM-INP medical, nursing, social work and psychology areas in said period.

The patients were classified according to the severity of the clinical presentation, based on the presence of cerebral edema and the need to be treated at the pediatric intensive care unit (PICU). This way they were classified in three groups:

1. Moderate AHT, without cerebral edema and not requiring care at the $\mathrm{PICU}$.

2. Severe AHT, with cerebral edema that required care at the PICU.

3. Fatal AHT, with cerebral edema that caused death (Table 1).

The cost of used medical resources was calculated with the values of the tabulator costs for recovery rates at level 6 of the National Institute of Pediatrics (INP), expressed in Mexican pesos. This tabulator at level 6 considers services total cost, both direct and indirect, and is adjusted annually according to inflation. For its calculation, macrocosting and microcosting combined techniques are used. ${ }^{26,27}$ The procedure for the calculation of these fees adheres to the Federation Income Law and this in turn to the General Statute of Health. ${ }^{26}$ The cost of more immediate complications (other diagnoses that develop owing to the severity of the condition) related to AHT and that are part of AHT care is included in this calculation.

The same procedure was used to calculate the cost that patients paid to the institution according to their assigned level.

To establish the cost for the stay at different departments, the cost per bed-day was used, where direct costs during patient hospitalization are considered, and this includes medications, wound dressing, procedures, resident physicians' and nursing staff intervention, except for the children's feeding. ${ }^{28}$

Since in this economic evaluation patients treated at different years were included, the values of the costs of the monetary nominal (current) units were converted to real (constant) units in order to eliminate the effect produced by inflation (they were deflated). To carry out the deflation of the cost value of each 
Table 2. Amount of resources used in the medical care of 14 patients diagnosed with abusive head trauma during their hospitalization, at the moment of diagnosis

\begin{tabular}{|c|c|c|c|c|c|c|c|c|}
\hline \multirow[t]{2}{*}{ Resource that generated cost } & \multicolumn{2}{|c|}{ Moderate AHT } & \multicolumn{2}{|c|}{ Severe AHT } & \multicolumn{2}{|c|}{ Fatal AHT } & \multicolumn{2}{|c|}{ Total } \\
\hline & Median & Min-max & Median & Min-max & Median & Min-max & Median & Min-max \\
\hline Days of emergency department stay & 0.50 & $0-5$ & 1 & $0-11$ & 5 & $2-9$ & 2.5 & $0-11$ \\
\hline Days of hospitalization area stay & 29.5 & $13-31$ & 34 & $20-117$ & 0 & 0 & 16.5 & $0-117$ \\
\hline Days of PICU stay & 0 & 0 & 13 & $1-25$ & 0 & 0 & 0 & $0-25$ \\
\hline Number of laboratory tests & 4.5 & $3-8$ & 67 & $59-81$ & 16 & $5-34$ & 16 & $3-81$ \\
\hline Number of imaging examinations & 7.5 & $5-11$ & 9 & $6-17$ & 7.5 & $4-11$ & 8.5 & $4-17$ \\
\hline Number of surgical procedures & 0.5 & $0-1$ & 1.5 & $0-4$ & 0.5 & $0-1$ & 1 & $0-4$ \\
\hline Number of consultations with subspecialties & 7 & $5-9$ & 7 & $7-10$ & 5.5 & $4-8$ & 7 & $4-10$ \\
\hline
\end{tabular}

$\mathrm{AHT}=$ abusive head trauma, $\mathrm{PICU}=$ pediatric intensive care unit.

annually used resource per patient, the annual deflator coefficient was calculated (Fig. 1), with the values of the quota tabulator for recovery of the INP in 2001 being taken as a basis. This yielded the real value as a result (Fig. 2).

\section{Cost calculation procedure}

Using the down-up approach, ${ }^{25}$ cost generators that were directly related to medical care were identified: days of hospital stay, number of consultations per specialist, surgical procedures and laboratory and imaging exams performed. The cost of each component was separately estimated and then added to obtain the total cost. ${ }^{29}$ The cost-of-illness analysis was carried out in two stages: in the first one, the used medical resources that were cost generators were quantified (Table 2). In the second one, the unit cost values corresponding to each resource were determined. For this, the nominal value was first obtained and subsequently the real value (deflated).

Direct medical costs were estimated ${ }^{30}$ by multiplying the real value of each medical resource used by its frequency of use (Fig. 3). Total costs and per group were calculated in Mexican pesos, and subsequently they were converted to international dollars (GearyKhamis dollar monetary unit), with the equivalence cost of 9.34 Mexican pesos of December 31, 2001 (base year for the calculation in Mexican pesos) issued by the World Bank therefore being used. ${ }^{31}$

\section{Statistical analysis}

The data analysis was performed with the SPSS software, version 21.

$$
\text { Deflator coeff. }=\frac{C P I_{f}}{C P I_{i}}
$$

Where:

Deflator coeff. $=$ deflator coefficient.

$\mathrm{CPI}_{\mathrm{f}}=$ final consumer price index (CPIs of the years the patients were attended to were used).

$\mathrm{CPI}_{\mathrm{i}}=$ initial consumer price index (the $2001 \mathrm{CPI}$ was used)

Figure 1. Deflator coefficient calculation. ${ }^{28 F}$

$$
R V=\frac{N C}{\text { Deflator coeff }}
$$

Where:

$\mathrm{RV}=$ real value.

$\mathrm{NC}=$ nominal cost.

Deflator coeff. $=$ deflator coefficient.

Figure 2. Deflation calculation.

A descriptive statistical analysis was carried out for the total sample and by analysis groups. Frequencies and percentages were calculated for patient characteristics' variables. For age and amount of used resources, median, minimum and maximum values were used. For the costs, the mean and standard deviation were calculated, as well as median, minimum and maximum values (due to the data distribution).

To identify significant differences between groups and contrast the hypothesis of equality between them, the Kruskal-Wallis nonparametric test was performed, with a $p$-value of $<0.05$ being considered to be statistically significant. For sensitivity analysis, the 


$$
C T_{j k w} \Sigma_{i=1}^{n} Q R_{j k i}{ }^{*} P R_{j k i}-
$$

Where:

CT = total cost for the care of event $j$, for the $k$ individual, with the w health condition.

$\mathrm{QR}=$ amount of resource $i$ used for the medical care of a $j$ medical event of patient $k$ with the $w$ medical condition.

$\mathrm{PR}=$ resource $i$ price or unit cost.

$i=$ resources used to carry out medical care $\{1,2 \ldots . . n\}$.

$j=$ type of medical resource (1. Days of hospital stay, 2. Number of consultations per specialist. 3. Performed surgical procedures, 4. Laboratory tests performed and 5 . Imaging tests performed). $k=$ Patients $\{1,2 \ldots n\}$.

Figure 3. Deflation calculation.

calculation was carried out by severity strata (moderate, severe and fatal $\mathrm{AHT}$ ).

\section{Results}

Fourteen patients with confirmed diagnosis of AHT were identified, out of which 10 (71\%) were males; median age was 6 months (minimum 2 and maximum 14); 6 patients (43\%) died during their stay at the emergency department, median hospital length of stay was 22 days (minimum 2, maximum 129). Other patient characteristics are described in Table 1.

Cases with severe AHT represented a higher total medical care average cost $(105,794.88 \pm 33,201.91$ Mexican pesos) in comparison with the group with moderate AHT $(37,012.95 \pm 7154.87)$ and with the group with fatal AHT $(18,595.04 \pm 6424.47)(p<0.01)$.

The breakdown of the cost of each resource is shown in Table 3. The cost in international dollars is shows in Table 4.

The cost for hospital stay was also higher in the group with severe AHT $(52,803.15 \pm 29,633$.69 Mexican pesos) $(p<0.01)$ than in patients with moderate AHT $(22,650.00 \pm 6786.35)$ and the group with fatal AHT, the cost of which was the lowest $(4174.55 \pm$ 2421.21) since their hospital stay was shorter, with a median of 2.5 days (0-11).

Regarding laboratory tests, there was no difference $(p>0.05)$ between the costs in patients: moderate AHT, $892.05 \pm 397.59$ Mexican pesos; severe AHT, 23,517.73 \pm 9465.91 and fatal AHT, $4752.71 \pm$ 3270.27 .

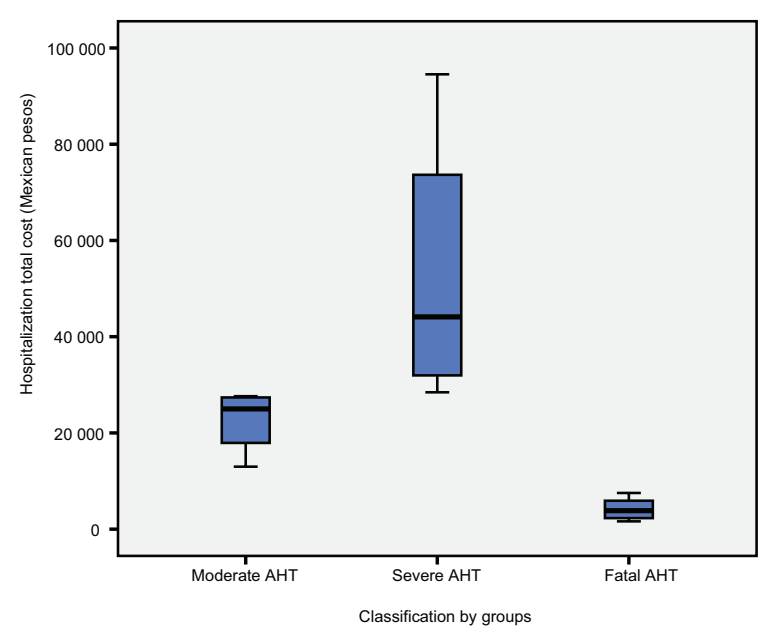

Figure 4. Sensitivity analysis (Kruskal-Wallis test with $p<0.05$ ).

Neither did the costs for imaging examinations show differences $(p>0.05)$ between the three groups: moderate AHT, $7175.56 \pm 4953.61$ Mexican pesos; severe AHT, 10,040.05 \pm 6285.74 and fatal AHT, $5372.96 \pm$ 2294.97.

In the surgical procedures, the cost also showed no differences ( $p>0.05)$, between groups: severe AHT, 16,327.77 $\pm 12,522$ Mexican pesos; moderate AHT, $3378.32 \pm 3996.57$ and fatal AHT, $242.68 \pm 2626.69$.

Neither did the cost for the consultations with different subspecialists show differences between groups: $2911.96 \pm 657.94$ Mexican pesos in moderate AHT, $3105.73 \pm 692.99$ in severe AHT and $1490.36 \pm 725.69$ in fatal AHT.

Total cost for the care of all 14 patients was $665,467.98$ Mexican pesos (71,249.25 international dollars). The amount paid to the institution for the care of the patients was $65,360.58$ Mexican pesos, which means that $90.17 \%(600,107.4$ Mexican pesos) of the cost of care was subsidized.

The sensitivity analysis showed a difference $(p<0.01)$ in total cost of care between the different severity strata (Fig. 4).

\section{Discussion}

In this study, partial direct costs of the medical care involved with the care of patients with AHT are shown in a disaggregated way, unlike the analyses thus far referred (which describe them globally). This breakdown included the number of days of hospital stay, the required surgical procedures, the different laboratory and imaging studies and their number in these patients, as well as the number of specialists, 


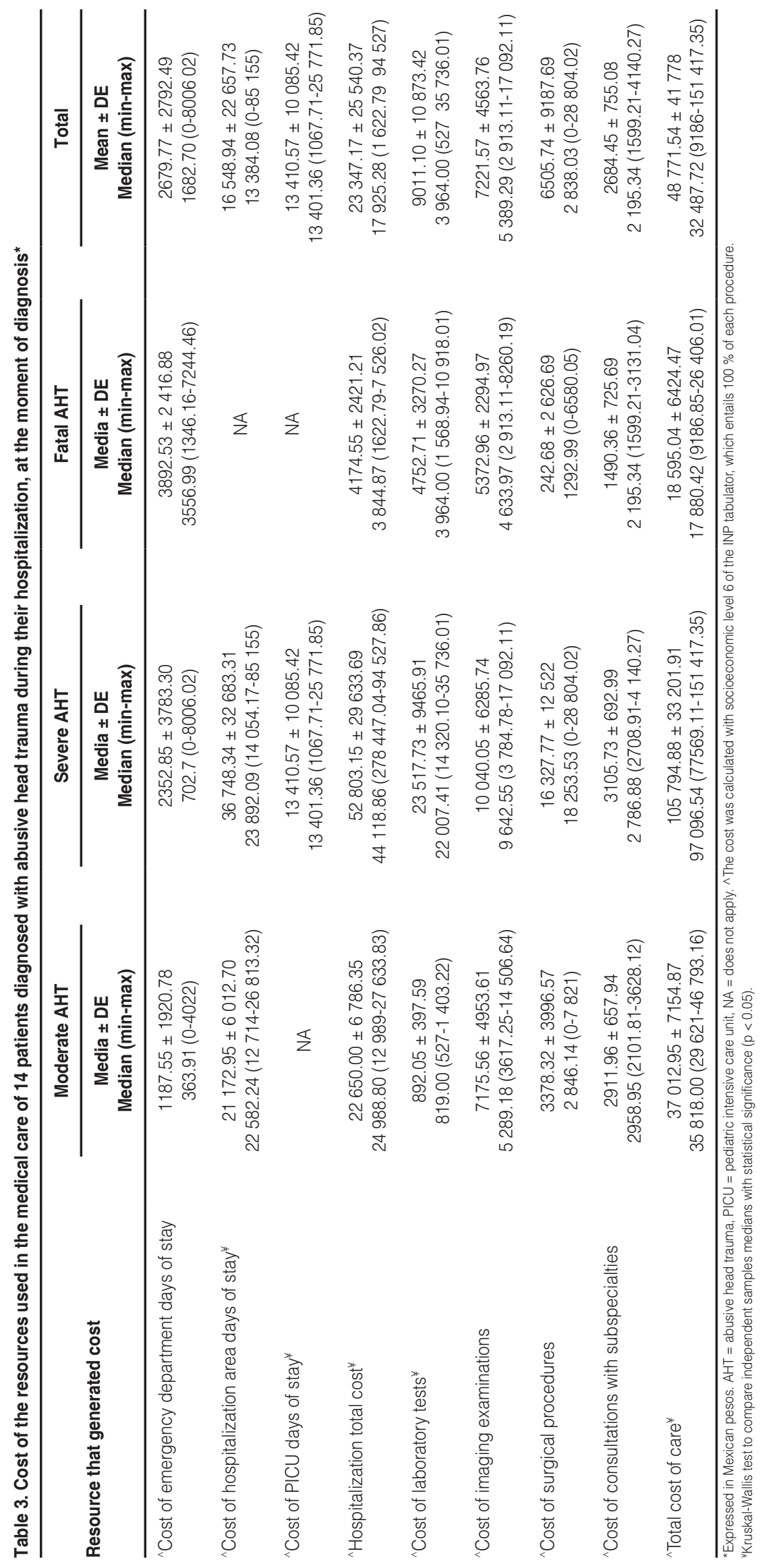




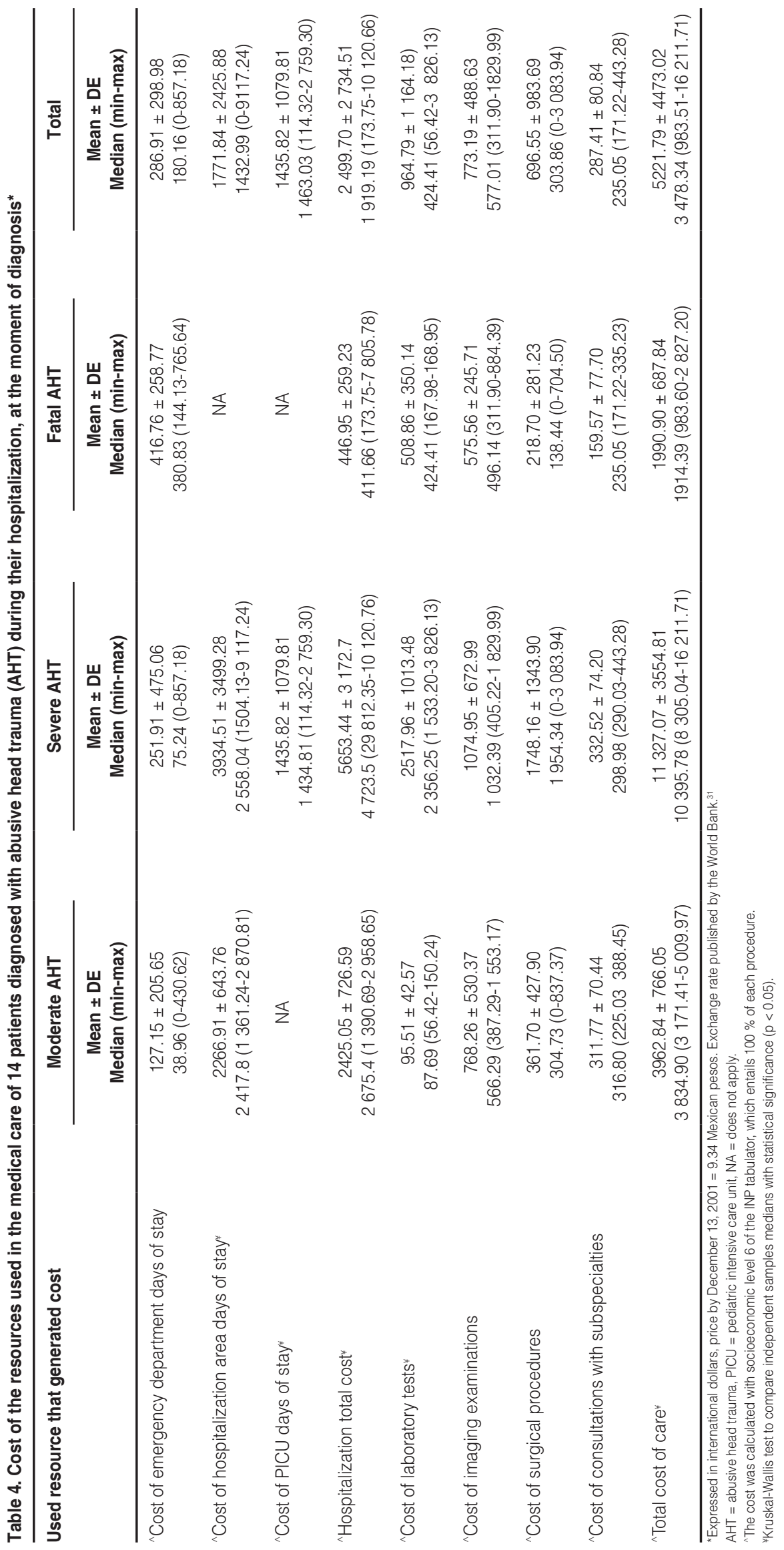


mainly in critical medicine and neurosurgery, whose intervention is necessary. This explains why the cost of medical and surgical care it is that high. ${ }^{21-24}$

Taking into account the severity of these patients' clinical presentation, prolonged hospitalization is explained, as well as the need for them to be cared for in the pediatric critical medicine department (emergency and intensive care areas) and that most of them require at least one surgical procedure, in which we agree with Miller and Peterson. ${ }^{22,24}$ In the children who survived, the severity of the condition determined hospital stay duration, which was longer in children with severe AHT.

In these patients, the establishment and surveillance of the metabolic condition and nosocomial infections explains the number of laboratory tests, which generates a high cost, especially when they are cared for in the PICU. Among the imaging studies, the performance of 32 cranial CT scans, 32 radiographs of different parts of the body and diverse ultrasounds stood out. All the studies were indispensable for the neurological, ocular and bone condition of the patients, as well as the aggression modality, to be specified.

The children underwent various surgical procedures, mainly cranial interventions, to solve the existence of depressed fractures, hematomas and hygromas. ${ }^{24}$ The number of specialists that intervened in the care of these patients was important (an average of 7 per patient), which elevated the cost of their care.

The investigation of cases with AHT in our setting has been oriented towards specific knowledge of the fundamental characteristics in the medical pediatric, social and legal fields. In the clinical area, AHT-triggering factors, the severity of the clinical presentation, the studies required to specify the diagnosis and medical-social-legal management of each patient have been described. ${ }^{10}$

One aspect of this form of child abuse that has been studied in other countries is that related to specifying the cost required for the comprehensive management of patients who are AHT victims. ${ }^{23,32-34}$ Initial hospitalization costs reported by some researchers range from 18,000 to 70,000 dollars per child and average medical costs can exceed 300,000 dollars per child. ${ }^{35}$ Medical and administrative costs required for longterm care exceed 300,000 and 1000,000 dollars per case, respectively. ${ }^{36}$ In Mexico, no study addressing the direct cost of the medical care of patients with AHT in a tertiary care pediatric hospital center had been carried out.
The severity of the clinical presentation of this modality of physical abuse requires attention in three specific hospitalization areas (emergency, PICU and hospitalization areas), the intervention of doctors with various specialties and the performance of very specific laboratory and imaging studies; therefore, only tertiary care pediatric hospital institutions can provide the comprehensive care this type of patients require, with the consequent economic impact for the institution. In addition to the above, if these children survive, they will have neurological, visual, auditory and osteoarticular sequelae of variable degrees and severity, which require specialized medical and paramedical care for a prolonged period, with the consequent economic burden for the family and the health sector. Although there are studies in other countries in this sense, no one completely covers the specific costs of immediate and long-term comprehensive care, since, in general, one or several situations of child abuse are analyzed. ${ }^{23,37}$

The costs that have been able to be established in this study allow to show that the expenditure is rather elevated for our setting, as it occurs in other parts of the world, where the cost is established in dollars. Therefore, we insist on the relevance of supporting to the maximum the development of preventive programs for child abuse and specifically for AHT, since their application will surely be more profitable than to invest in the care and correction of the morbidity and mortality of these patients.

\section{Study limitations}

As mentioned in the methods section, the cost of medical care that was calculated for these patients included the most immediate complications (other diagnoses), which were not separately calculated and the cost of these diagnoses was attributed to the underlying diagnosis (AHT).

Since having uniform information on the follow-up of these patients in the consulted sources of information was not possible, a cross-sectional study was carried out, which is why the long-term cost could not be established. It is advisable for an analysis that includes follow-up to be performed in order to establish the probability of years of survival and the cost of the care of sequels.

The calculated costs do not reflect the national cost because the recovery fee tabulator of a tertiary care hospital such as the National Institute of 
Pediatrics was used. Although it is pertinent to clarify that usually this type of patients are attended to at tertiary care institutions, owing the seriousness they arrive with at the moment of asking for medical care.

The complete analysis of the cost of an illness should ideally include direct, indirect and intangible costs; however, the present investigation was carried out focusing on prevalence rather than incidence, ${ }^{38,39}$ which includes the lifelong cost estimate. Carrying out this type of analysis in order to complete the economic panorama that represents this pathology is suggested, considering that in the past decades, health services production costs have increased, both in absolute figures per capita, and as a fraction of the internal gross product and in relation to inflation. ${ }^{40}$

\section{Conclusions}

The direct economic cost of hospital care for the 14 patients diagnosed with AHT was high for our setting, although it is not comparable with those reported in the United States.

In general terms, it is closely related to the severity of the clinical presentation, which entails prolonged hospital stay, especially at critical medicine departments (emergency and intensive care areas), a significant volume of laboratory and imaging tests, and the participation of different specialists for its care.

The need to develop preventive programs is insisted on, considering that this pathology is preventable in $100 \%$ of cases.

\section{Acknowledgements}

We thank the medical interns on social service María Teresa Arias González and Víctor Alam Gaona Badillo, as well as business administration intern Julio César Huerta Navarro, for his participation in the review of fee recovery tabulators per year and in the calculation of the real prices of each service, as well as in the search for bibliography.

\section{References}

1. Caffey J. The whiplash shaken infant syndrome: manual shaking by the extremities with whiplash-induced intracranial and intraocular bleedings, linked with residual permanent brain damage and mental retardation. Pediatrics. 1974:54:396- 403.

2. Harding B, Risdon RA, Krous HF. Shaken baby syndrome. BMJ. 2004;328:720-721.

3. American Academy of Pediatrics: Committee on Child Abuse and $\mathrm{Ne}-$ glect. Shaken baby syndrome, rotational cranial injuries: technical report. Pediatrics. 2001;108:206-210.
4. Karibe H, Kameyama M, Hayashi T, Narisawa A, Tominaga T. Acute subdural hematoma in infants with abusive head trauma: a literature review. Neurol Med Chir (Tokyo). 2016;56:264-273.

5. Rufo-Campos M. El síndrome del niño sacudido. Cuad Med Forense. 2006;12:39-45.

6. Mian M, Shah J, Dalpiaz A, Schwamb R, Miao Y, Warren K, et al. Shaken baby syndrome: a review. Fetal Pediatr Pathol. 2015;34:169-175.

7. King JW, MacKay M, Sirnick A, Canadian Shaken Baby Study Group. Shaken baby syndrome in Canada: clinical characteristics and outcomes of hospital cases. CMAJ. 2003;168:155-159.

8. Sieswerda-Hoogendoorn T, Boos S, Spivack B, Bilo RA, Van-Rijn RR. Educational paper: abusive Head Trauma Part I. Clinical aspects. Eur J Pediatr, 2012;171:415-423,

9. Bhardwaj G, Chowdhury V, Jacobs MB, Moran KT, Martin FJ, Coroneo MT. A systematic review of the diagnostic accuracy of ocular signs in pediatric abusive head trauma. Ophthalmology. 2010;117:983-992.

10. Loredo-Abdalá A, Casas-Muñoz A, Trejo-Hernández J, Melquiades-Parra I, Martín-Martín V. Síndrome del niño sacudido: cuadro clínico y evolución de 17 casos en el Instituto Nacional de Pediatría. Acta Pediatr Mex. 2015;36:72-80.

11. Han BK, Towbin RB, De-Courten-Myers G, McLaurin RL, Ball WS. Reversal sign on $\mathrm{CT}$ : effect of anoxic/ischemic cerebral injury in children. AJNR Am J Roentgenol. 1990;154:361-368.

12. Perea-Martínez A, Loredo-Abdalá A, Guicho-Alba E. El niño sacudido-impactado una modalidad del maltrato físico severo. En: Loredo-Abdalá A. Maltrato en niños y adolescentes. México: Editores de Textos Mexicanos; 2004.

13. Delgado FA, Lavalle VA, Torres GS. Síndrome del niño sacudido. Bol Med Hosp Infant Mex. 1995;52:481-484.

14. Block R, Christian CW, Committee Child Abuse and Neglect, American Academy of Pediatrics. Abusive head trauma in infant and children. Pediatrics. 2009:123:1409-1411.

15. Chiesa A, Dunhaime AC. Traumatismo craneoencefálico por maltrato. Pediatr Clin N Amer. 2009;56:317-331.

16. Guthkelch AN. Infantile subdural hematoma and its relationship to whiplash injuries. Br Med J. 1971:2:430-431.

17. Caffey J. Multiple fractures in the long bones of infants suffering from chronic subdural hematoma. Am J Roentgenol Radium Ther. 1946;56:163-173.

18. Silverman FN. The roentgen manifestations of unrecognized skeletal trauma in infants. Am J Roentgenol Radium Ther Nucl Med. 1953;69:413-427.

19. Ommaya AK, Faas $F$, Yamell $P$. Whiplash injury and brain damage: an experimental study. JAMA. 1968;204:285-289.

20. Drummond M. Cost-of-illness studies: a major headache? Pharmacoeconomics. 1992;2:1-4.

21. Brown DS, Fang X, Florence CS. Medical costs attributable to child maltreatment: a systematic review of short-and long-term effects. Am J Prev Med. 2011;41:627-635.

22. Miller TR, Steinbeigle R, Lawrence BA, Peterson C, Florence C, Barr M, et al. Lifetime cost of abusive head trauma at ages 0-4, USA. Prev Sci. 2017;6:1-10.

23. Peterson C, Xu L, Florence C, Parks SE, Miller TR, Barr RG, et al. The medical cost of abusive head trauma in the United States. Pediatrics. 2014;134:91-99

24. Peterson C, Xu L, Florence C, Parks SE. Annual cost of U.S. hospital visits for pediatric abusive head trauma. Child Maltreat. 2015;20:162-169.

25. Jo C. Cost-of-illness studies: concepts, scopes, and methods. Clin Mol Hepatol. 2014;20:237-337.

26. Secretaría de Salud. Manual institucional y guía sectorial para la aplicación de la metodología de costos. México: Secretaría de Salud; 2011.

27. Instituto Nacional de Pediatría. Procedimiento para la actualización de cuotas de recuperación. En: Manual de procedimientos de la Dirección de Planeación. México: Instituto Nacional de Pediatría; 2011.

28. Yirepa, Finanzas Básicas. [Sitio web]. Deflactar. Disponible en: http:// yirepa.es/deflactar.html.

29. Baeza-Cruz G, Peniche-Otero G, Alva-Esqueda ME, Naranjo-Muedano M, Soria-Suárez N, Morales-Flores HJ. Análisis de costo de la enfermedad, del tratamiento, las complicaciones e intervenciones de la hipercolesterolemia en México en 2016. Value Health Reg Issues. 2018;17:56-63.

30. Tarricone R. Cost-of-illness analysis. What room in health economics? Health Policy. 2006;77(1):51-63.

31. Base de datos el programa de comparación internacional. Factor de conversión de PPA, PIB (UMN por \$ a precios internacionales). Tasa de cambio oficial (UMN por US\$, promedio para un periodo). EE. UU.: Banco Mundial; 2018.

32. Fang X, Brown DS, Florence CS, Mercy JA. The economic burden of child maltreatment in the United States and implications for prevention. Child Abuse Negl. 2012;36:156-165.

33. Boop S, Axente M, Weatherford B, Klimo P. Abusive head trauma: an epidemiological and cost analysis. J Neurosurg Pediatr. 2016;18:542-549. 
34. Friedman J, Reed $\mathrm{P}$, Sharplin $\mathrm{P}$, Kelly $\mathrm{P}$. Primary prevention of pediatric abusive head trauma: a cost audit and cost-utility analysis. Child Abuse Negl. 2012;3:760-770

35. Dias M, Smith K, DeGuehery K, Mazur P, Li V, Shaffer ML. Preventing abusive head trauma among infants and young children: a hospital-based, parent education program. Pediatrics. 2005;115:e470-e477.

36. Fujiwara T. Effectiveness of public health practices against shaken baby syndrome/abusive head trauma in Japan. Public Health. 2015 129:475-482.

37. Ettaro L, Berger RP, Songer T. Abusive head trauma in young children: characteristics and medical charges in a hospitalized population. Child Abuse Negl. 2004;28:1099-1111.
38. Hartunian NS, Smart CN, Thompson MS. The incidence and economic costs of cancer, motor vehicle injuries, coronary heart disease, and stroke: a comparative analysis. Am J Public Health. 1980;70: 1249-1260.

39. Sagastuy B. Retos de los hospitales en el marco de la salud universal y el desarrollo sostenible. En: Fajardo-Ortiz G. Nuevas fronteras en el pensamiento y práctica de la administración hospitalaria. México: Academia Nacional de Medicina/Editorial Intersistemas; 2018.

40. Augustovski F, García S, Pichon-Riviere A. Estándares consolidados de reporte de evaluaciones económicas sanitarias: versión en español de la lista de comprobación CHEERS. Value Health Reg Issues. 2013;16:231-250. 